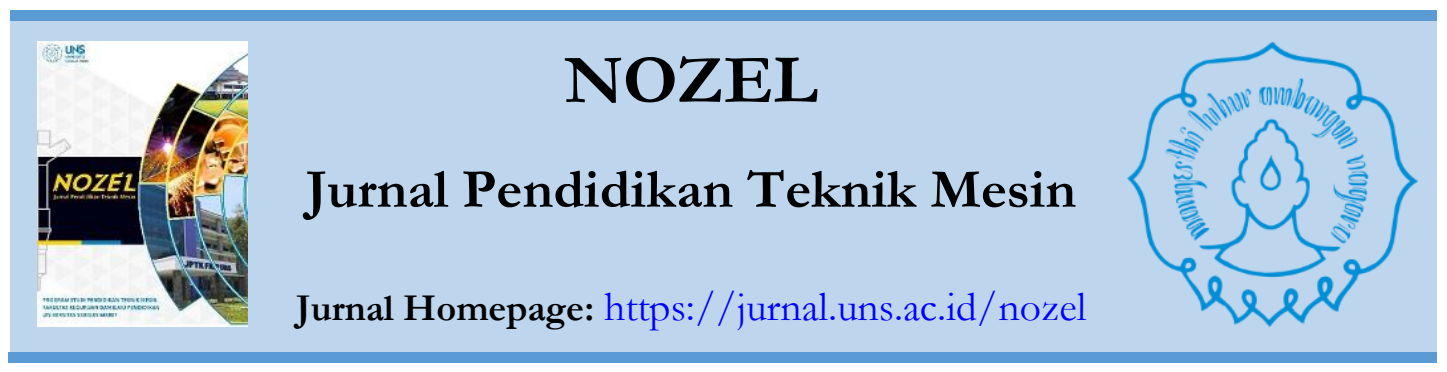

\title{
ANALISIS PERFORMA BOILER BASUKI BERDASARKAN RASIO ANTARA BAHAN BAKAR DAN STEAM DI PT. INDO ACIDATAMA Tbk.
}

\author{
Maedanu Fasola Putra ${ }^{1}$, Danar Susilo Wijayanto ${ }^{1}$, Nugroho Agung Pambudi ${ }^{1}$ \\ ${ }^{1}$ Program Studi Pendidikan Teknik Mesin, FKIP, Universitas Sebelas Maret Surakarta \\ e-mail: maedanuputra@gmail.com
}

\begin{abstract}
The research aims to investigate the condition of Basuki boiler based on the ratio between fuel consumption and steam production. The research used quantitativedescriptive method. The population of this research was daily record of Basuki boiler. The sample was daily record of Basuki boiler performance for 1 year (February 2015 to January 2016). The sample was taken using purposive sampling method. The research analyzed the ability of fuel to produce a ton (1000 kilograms) of steam. The ability of fuel was depended on the highest heating value (HHV) and water contain in the coal. Based on the result of the research, it can be concluded that Basuki boiler condition based on its ratio between fuel consumption and steam production was good, because the ratio that shown (144.09) was less than the company's target (150), it meant that the boiler only used 144.09 kilograms of coal to produce a ton of steam. The average of fuel consumption for 1 year was $1,484.99 \mathrm{~kg} / \mathrm{h}$ and the average of steam production was $10,305.76 \mathrm{~kg} / \mathrm{h}$.
\end{abstract}

Keywords: Basuki boiler, ratio, fuel consumption, steam production

\section{A. PENDAhuluan}

Bahan bakar fosil merupakan salah satu sumber energi yang tidak terbarukan, itu artinya ketika persediaannya sudah habis maka tidak bisa didaur ulang dan digunakan kembali. Bahan bakar fosil juga masih menjadi sumber energi yang paling banyak digunakan di bumi. Lebih dari $80 \%$ sumber energi yang digunakan di bumi berasal dari bahan bakar fosil, dan seiring dengan meningkatnya kebutuhan manusia akan energi penggunaan bahan bakar fosil akan terus meningkat padahal jumlahnya semakin berkurang.

Salah satu pengguna bahan bakar fosil tertinggi terdapat pada sektor industri. Pada dunia industri penggunaan bahan bakar fosil biasa digunakan untuk menyuplai energi pada alat-alat produksi. Salah satu alat produksi yang menggunakan bahan bakar fosil adalah boiler. Boiler merupakan alat yang digunakan untuk memanaskan air hingga 
menjadi uap. Sumber energi yang digunakan pada boiler berupa bahan bakar yang umumnya berupa berasal fosil seperti minyak dan batu bara.

Boiler terdiri dari berbagai komponen, dan sebagaimana alatciptaan manusia lainnya seiring berjalannya waktu alat tersebut akan mengalami gangguan atau kerusakan. Langkah penanganan yang baik harus dilakukan dengan analisis terhadap kinerja boiler terlebih dahulu. Salah satu metode yang dapat digunakan adalah dengan menganalisis rasio antara konsumsi bahan bakar dengan produksi steam. Rasio tersebut menunjukkan kemampuan boiler dalam memanfaatkan panas dari bahan bakar untuk menghasilkan steam. Analisis rasio perlu dilakukan karena tidak hanya dapat mengetahui kondisi dari boiler tapi juga mengetahui kualitas dari bahan bakar yang digunakan.

\section{Deskripsi Boiler}

Penelitian ini meneliti siklus energi pada boiler dengan tipe Bubbling Fluidized Bed Combustion. Boiler tersebut digunakan untuk menghasilkan uap yang akan digunakan untuk proses fermentasi dan destilasi pada industri Etanol. Bahan bakar yang digunakan pada boiler merupakan batu bara jenis bituminous yang dihaluskan. Boiler tersebut merupakan boiler tipe gabungan pipa api dan pipa air. Proses yang terjadi pada boiler ditunjukkan dengan gambar 1 .

Proses yang terjadi pada boiler dimulai dari air umpan setelah mengalami pemanasan awal pada pre-heater dan deaerator dipompa masuk ke boiler. Air umpan yang masuk boiler bersuhu $96^{\circ} \mathrm{C}$ akan melewati shell pada boielr pipa api terlebih dahulu. Sebagian air umpan akan menguap dan uap yang dihasilkan akan dialirkan menuju ke steam header. Sebagian lainnya yang belum menjadi uap akan dialirkan ke pipa pada membrane wall. Pada membrane wall air umpan yang belum menjadi uap akan dipanasi hingga menjadi uap. Pemanasan pada membrane wall memanfaatkan panas langsung dari dapur pembakaran boiler dengan media transfer panas berupa pasir silika.

\section{B. METODE}

Penelitian ini menggunakan metode analisis deskriptif kuantitatif, dimana dalam penelitian ini melakukan analisis pada rasio antara konsumsi bahan bakar dan produksi steam. Untuk menganalisis hal tersebut maka diperlukan sampel berupa data record harian kinerja boiler untuk periode Februari 2015 s.d. Januari 2016. Data yang ada pada record harian selanjutnya dikembangkan dan dianalisis 
untuk dapat mendeskripsikan performa boiler. Pengembangan data yang dilakukan menggunakan rumus-rumus berikut:

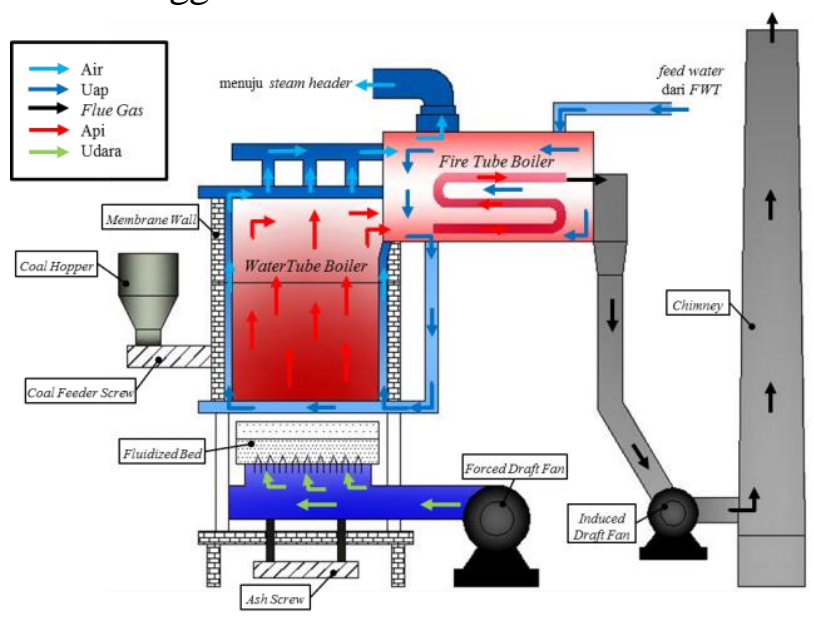

Gambar 1. Siklus kerja boiler tipe Fluidized Bed Combustion

\section{Rasio antara Konsumsi Bahan Bakar}

\section{dan Produksi Steam}

Konsumsi Bahan Bakar ( $\left.\mathrm{m}_{f u e l}\right)$

$$
\dot{\mathrm{m}}_{f u e l}=\frac{m_{f u e l}(\mathrm{~kg})}{T(\mathrm{jam})}(\mathrm{kg} / \mathrm{jam})
$$

Produksi Steam $\left(\mathrm{m}_{\text {steam }}\right)$

$$
\dot{\mathrm{m}}_{\text {steam }}=\frac{m_{\text {steam }}(\mathrm{kg})}{T(\mathrm{jam})}(\mathrm{kg} / \mathrm{jam})
$$

Rasio (R)

$R=\frac{1000 x \mathrm{~m}_{\text {fuel }}(\mathrm{kg} / \mathrm{jam})}{\dot{\mathrm{m}}_{\text {steam }}(\mathrm{kg} / \mathrm{jam})}(\mathrm{kg} \mathrm{bb} /$ Ton steam)

\section{HASIL DAN PEMBAHASAN}

Data record harian kinerja boiler Basuki periode Februari 2015 s.d. Januari 2016 disajikan dalam tabel 1. Data pada tabel 1 selanjutnya dikembangkan untuk dapat menentukan performa boiler berdasarkan rasio antara konsumsi bahan bakar dan produksi steam, analisis energi dan analisis eksergi. Data pada tabel 1 merupakan data primer yang diperoleh dari data record harian boiler Basuki.

Tabel 1. Record Data Boiler Basuki

\begin{tabular}{|c|c|c|c|c|c|}
\hline Bulan & Jam & $\begin{array}{l}\text { Batu } \\
\text { Bara }\end{array}$ & $\begin{array}{l}\text { Feed } \\
\text { water }\end{array}$ & $\begin{array}{c}\text { Produksi } \\
\text { Steam }\end{array}$ & Tekanan \\
\hline & & $(\mathrm{kg})$ & $\left(\mathrm{m}^{3}\right)$ & $(\mathrm{kg})$ & (bar) \\
\hline Feb '15 & 512 & 763.570 & 6.132 & 5.518 .800 & 7,76 \\
\hline Mar '15 & 714 & 1.195 .560 & 9.145 & 8.239 .500 & 7,39 \\
\hline Apr ' 15 & 707 & 975.605 & 7.681 & 6.912 .900 & 7,72 \\
\hline Mei '15 & 528 & 596.720 & 4.582 & 4.123 .800 & 7,56 \\
\hline Jun '15 & 720 & 920.030 & 8.011 & 7.218 .800 & 7,64 \\
\hline Jul '15 & 148 & 196.220 & 1.384 & 1.245 .600 & 7,46 \\
\hline Agt ' 15 & 229 & 417.990 & 3.272 & 2.944 .800 & 6,67 \\
\hline Sep ' 15 & 545 & 1.016 .420 & 7.859 & 7.073 .100 & 7,37 \\
\hline $0 \mathrm{kt}$ ' 15 & 464 & 603.610 & 4.739 & 4.265 .370 & 7,24 \\
\hline Nov '15 & 685 & 1.040 .280 & 8.174 & 7.356 .157 & 7,14 \\
\hline Des ' 15 & 727 & 1.173 .530 & 9.054 & 8.148 .152 & 7,22 \\
\hline Jan '16 & 741 & 1.049 .500 & 7.853 & 7.067 .465 & 6,84 \\
\hline Total & 6720 & 9.949 .035 & 77.886 & 70.105 .444 & 88,01 \\
\hline $\begin{array}{c}\text { Rata- } \\
\text { rata }\end{array}$ & 560 & 835.042 & 6.523 & 5.871 .513 & 7,33 \\
\hline
\end{tabular}
periode Februari 2015

\section{Konsumsi Bahan Bakar}

Konsumsi bahan bakar merupakan jumlah bahan bakar (batu bara) yang diperlukan setiap jam-nya untuk pembakaran yang digunakan mengubah feed water menjadi uap. Konsumsi bahan bakar oleh boiler Basuki mengalami perubahan tiap bulannya dikarenakan jumlah jam dan hari beroperasinya boiler tidak selalu sama tiap bulannya. Selain itu, kerja boiler untuk menghasilkan steam setiap bulannya juga berubah-ubah sesuai dengan kebutuhan steam yang dibutuhkan perusahaan. Konsumsi bahan bakar boiler Basuki selama 1 tahun ditunjukkan oleh tabel 2. 
Tabel 2.Konsumsi Bahan Bakar

\begin{tabular}{ccccc}
\hline \multirow{2}{*}{ Bulan } & \multicolumn{3}{c}{ Total } & Rata-rata \\
\cline { 2 - 5 } & $(\mathrm{kg})$ & (hari) & (jam) & (kg jam) \\
\hline Feb '15 & 763.570 & $22 / 28$ & 512 & $1.491,35$ \\
Mar '15 & 1.195 .560 & $30 / 31$ & 714 & $1.674,45$ \\
Apr '15 & 975.605 & $30 / 30$ & 707 & $1.379,92$ \\
Mei '15 & 596.720 & $24 / 31$ & 528 & $1.130,15$ \\
Jun'15 & 920.030 & $30 / 30$ & 720 & $1.277,82$ \\
Jul '15 & 196.220 & $8 / 31$ & 148 & $1.325,81$ \\
Agt '15 & 417.990 & $10 / 31$ & 229 & $1.825,28$ \\
Sep '15 & 1.016 .420 & $25 / 30$ & 545 & $1.864,99$ \\
Okt '15 & 603.610 & $22 / 31$ & 464 & $1.300,88$ \\
Nov '15 & 1.040 .280 & $30 / 30$ & 685 & $1.518,66$ \\
Des '15 & 1.173 .530 & $31 / 31$ & 727 & $1.614,21$ \\
Jan '16 & 1.049 .500 & $31 / 31$ & 741 & $1.416,33$ \\
\hline Rata-rata & $\mathbf{9 . 9 4 9 . 0 3 5}$ & $\mathbf{2 4 , 4 2}$ & $\mathbf{5 6 0}$ & $\mathbf{1 . 4 8 4 , 9 9}$ \\
\hline
\end{tabular}

Konsumsi bahan bakar dalam tabel 2 tersebut merupakan jumlah batu bara yang dipasok ke dalam dapur pembakaran boiler Basuki dalam satu jam. Data tersebut diperoleh dari merata-rata data harian dalam 1 bulan, dan dalam 1 tahun boiler Basuki rata-rata memerlukan $1.484,99 \mathrm{~kg}$ untuk 1 jam beroperasi.

\section{Produksi Steam}

Produksi steam merupakan jumlah steam yang dihasilkan dari penguapan feed water dengan menggunakan panas dari proses pembakaran batu bara. Jumlah steam yang dihasilkan oleh boiler Basuki berbeda-beda setiap jamnya. Hal tersebut tergantung pada banyaknya feed water yang dialirkan, jumlah bahan bakar yang dikonsumsi, dan kualitas atau nilai bakar dari bahan bakar itu sendiri. Steam yang dihasilkan rata-rata sebesar $90 \%$ dari feed water yang dipanaskan, $10 \%$ sisa feed water akan dibuang melalui saluran blowdown. Produksi steam oleh boiler Basuki dalam satu tahun ditunjukkan oleh tabel 3 .

Produksi steam oleh boiler Basuki setiap bulan mengalami perubahan karena disesuaikan dengan permintaan produksi oleh perusahaan. Data pada tabel 3 diperoleh dengan merata-rata data harian dalam 1 bulan. Boiler Basuki dalam 1 tahun rata-rata dapat memproduksi uap kering sebesar 10.305,76 kg tiap jamnya.

Tabel 3.Produk Steam oleh boiler Basuki

\begin{tabular}{ccccc}
\hline \multirow{2}{*}{ Bulan } & \multicolumn{2}{c}{ Total Feed water } & Rata-rata & Steam \\
\cline { 2 - 5 } & $\left(\mathrm{m}^{3}\right)$ & $(\mathrm{jam})$ & $\left(\mathrm{m}^{3} / \mathrm{jam}\right)$ & $(\mathrm{kg} / \mathrm{jam})$ \\
\hline Feb '15 & 6.123 & 512 & 11,98 & $10.778,91$ \\
Mar '15 & 9.145 & 714 & 12,81 & $10.126,75$ \\
Apr '15 & 7.681 & 707 & 10,86 & $9.777,79$ \\
Mei '15 & 4.582 & 528 & 9,19 & $7.810,28$ \\
Jun '15 & 8.011 & 720 & 11,13 & $10.026,11$ \\
Jul '15 & 1.384 & 148 & 9,35 & $8.416,22$ \\
Agt '15 & 3.272 & 229 & 14,29 & $13.077,73$ \\
Sep '15 & 7.859 & 545 & 14,42 & $12.978,17$ \\
Okt'15 & 4.739 & 464 & 10,21 & $9.192,61$ \\
Nov '15 & 8.174 & 685 & 11,93 & $10.738,92$ \\
Des '15 & 9.054 & 727 & 12,45 & $11.207,91$ \\
Jan '16 & 7.853 & 741 & 10,60 & $9.537,74$ \\
\hline Rata-rata & $\mathbf{7 7 . 8 7 7}$ & $\mathbf{5 6 0}$ & $\mathbf{1 1 , 6 0}$ & $\mathbf{1 0 . 3 0 5 , 7 6}$ \\
\hline
\end{tabular}

\section{Rasio antara Konsumsi Bahan Bakar}

\section{Dengan Produksi Steam}

Rasio yang dimaksud disini menjelaskan banyaknya bahan bakar yang digunakan oleh boiler untuk menghasilkan $1000 \mathrm{~kg}$ (1 Ton) uap kering. Rasio boiler Basuki yang telah berhasil dihitung disajikan dalam tabel 4 dan gambar 1. 
Tabel 4. Rasio Boiler Basuki

\begin{tabular}{ccccc}
\hline \multirow{2}{*}{ Bulan } & Batu bara & Feed water & Steam & \multirow{2}{*}{ Rasio } \\
\cline { 2 - 4 } & $(\mathrm{kg} / \mathrm{jam})$ & $\left(\mathrm{m}^{3}\right.$ /jam $)$ & $(\mathrm{kg} / \mathrm{jam})$ & \\
\hline Feb '15 & $1.491,35$ & 11,98 & $10.778,91$ & 138,36 \\
Mar '15 & $1.674,45$ & 12,81 & $10.126,75$ & 165,35 \\
Apr '15 & $1.379,92$ & 10,86 & $9.777,79$ & 141,13 \\
Mei '15 & $1.130,15$ & 9,19 & $7.810,28$ & 144,70 \\
Jun '15 & $1.277,82$ & 11,13 & $10.026,11$ & 127,45 \\
Jul '15 & $1.325,81$ & 9,35 & $8.416,22$ & 157,53 \\
Agt '15 & $1.825,28$ & 14,29 & $13.077,73$ & 139,57 \\
Sep '15 & $1.864,99$ & 14,42 & $12.978,17$ & 143,70 \\
Okt '15 & $1.300,88$ & 10,21 & $9.192,61$ & 141,51 \\
Nov '15 & $1.518,66$ & 11,93 & $10.738,92$ & 141,42 \\
Des '15 & $1.614,21$ & 12,45 & $11.207,91$ & 144,02 \\
Jan '16 & $1.416,33$ & 10,60 & $9.537,74$ & 148,50 \\
\hline Rata-rata & $\mathbf{1 . 4 8 4 , 9 9}$ & $\mathbf{1 1 , 6 0}$ & $\mathbf{1 0 . 3 0 5 , 7 6}$ & $\mathbf{1 4 4 , 0 9}$ \\
\hline
\end{tabular}

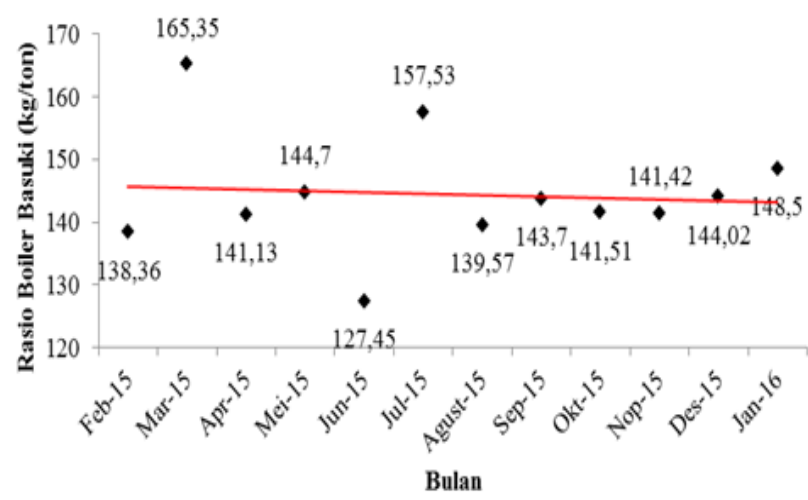

Gambar 2. Rasio Boiler Basuki

Rata-rata rasio yang ditunjukkan oleh boiler Basuki sebesar 144,09 kg batu bara/ Ton steam. Rasio terbaik diperoleh pada bulan Juni 2015 sebesar 127,45, sedangkan rasio terburuk terjadi pada bulan Maret 2015. Perusahaan dalam hal ini sudah memiliki standar Rasio yaitu 150. Mengacu pada hal tersebut, maka boiler Basuki menunjukkan performa yang cukup baik karena rata-rata rasio dalam satu tahun sebesar 144,09 yang artinya boiler Basuki hanya memerlukan 144,09 Kg batu bara untuk menghasilkan 1 Ton uap kering. Selain itu, trendline yang ditunjukkan pada gambar 1 juga menunjukkan rasio mengalami penurunan. Itu artinya dengan mempertahankan kondisi boiler yang ada saat ini maka diperkirakan rasio boiler akan masih di bawah target yang diberikan perusahaan.

\section{PENUTUP}

\section{Simpulan}

1. Performa boiler Basuki berdasarkan rasio antara bahan bakar dan produksi steam termasuk baik karena melebihi target yang telah ditentukan perusahaan (150) dengan nilai rasio boiler Basuki sebesar 144, yang artinya boiler Basuki memerlukan 144 $\mathrm{Kg}$ batu bara untuk menghasilkan satu ton uap kering (steam).

2. Rata-rata konsumsi batu bara dalam 1 tahun adalah $1.484,99 \mathrm{~kg} / \mathrm{jam}$ dan ratarata produksi uap kering sebesar $10.305,76 \mathrm{~kg} / \mathrm{jam}$.

\section{Saran}

1. Untuk penelitian sejenis yang akan dilakukan dapat menambahkan dan mengembangkan indikator yang dianalisis berkaitan dengan performa boiler, sehingga bahan yang dikaji untuk menentukan performa boiler dapat lebih luas.

2. Untuk penelitian selanjutnya dapat mengembangkan penelitiannya sampai 
pada upaya yang bisa dilakukan untuk meningkatkan performa boiler berdasarkan analis energi dan eksergi yang telah dilakukan.

3. Untuk penelitian selanjutnya juga dapat menggunakan data record untuk waktu yang lebih lama, sehingga semakin akurat

\section{DAFTAR PUSTAKA}

Astrawan, P. (2006). Panduan PKL, Utility Departement. Karanganyar: PT. INDO ACIDATAMA Tbk.

Astrawan, P. (2006). Instruksi Kerja, Operasional Boiler Basuki. Karanganyar: PT. INDO ACIDATAMA Tbk.
Muin, S. A. (1998). Pesawat-pesawat Konversi Energi I : Ketel Uap. Jakarata: Rajawali Press.

Rosen, Marc A. (2001). Energy and exergy based comparison of coal fired and nuclear steam power plants. Exergy Int. J. 1(3) (2001) 180-192. Diperoleh 07 Maret 2016, dari http://www.ewp.rpi.edu /hartford/ odells2/EP/Other/ references/.pdf Woodruff, E. B., Lammers, H. B. \& Lammers, T. F. (1998). Steam Plant Operation, Seventh Edition. New York:McGraw-Hill. 